\title{
A Triangular Approach to Integrate Research, Education and Practice in Higher Engineering Education
}

E.-P. Heikkinen*, J. Jaako** and J. Hiltunen***

Faculty of Technology, University of Oulu, Oulu, Finland

* Corresponding author. Address: Process metallurgy research group, PO Box 4300, FI90014 University of Oulu, Finland. Email: eetu.heikkinen@oulu.fi

** Address: Department of Mathematical Sciences, PO Box 3000, FI-90014 University of Oulu, Finland. Email: juha.jaako@ oulu.fi

*** Address: Systems engineering research group, PO Box 4300, FI-90014 University of Oulu, Finland. Email: jukka.hiltunen@oulu.fi 


\title{
A Triangular Approach to Integrate Research, Education and Practice in Higher Engineering Education
}

\author{
Separate approaches in engineering education, research and practice are not very \\ useful when preparing students for working life; instead, integration of education, \\ research and industrial practices is needed. A triangular approach (TA) as a \\ method to accomplish this integration and as a method to provide students with \\ integrated expertise is proposed. The results from the application of TA, both at \\ the course and programme level, indicate that the approach is suitable for \\ developing engineering education. The student pass rate for courses where TA \\ has been used has been higher than for previous approaches, and the student \\ feedback has been very positive. Although TA aims to take both theoretical and \\ practical aspects of engineering as well as research and education into account, \\ the approach concentrates mainly on activities and therefore leaves the goals of \\ these activities as well as the values behind these goals uncovered.
}

Keywords: chemical engineering, curriculum development, engineering education, environmental engineering

\section{Introduction}

University education in engineering, medicine, law and business aims at learning outcomes (Biggs and Tang 2007) that are both scientifically and professionally relevant in that specific field (i.e. for engineers, doctors, lawyers and businessmen). To achieve such learning outcomes, it is necessary to explicitly introduce and maintain a healthy balance between a discipline's theoretical (i.e. concerned with ideas and principles on which a particular subject is based) and practical (i.e. connected with real situations) sides as well as the connections between them. (e.g. Collin and Tynjälä 2003, Jakobsen and Bucciarelli 2007, Katajavuori et al. 2006, Leinhardt et al. 1995, Slotte and Tynjälä 2003, Tynjälä et al. 1997, Tynjälä et al. 2003, Tynjälä et al. 2005) In other words, educational and curricular development of both practically and theoretically sustainable university education requires a holistic view that takes into account the scientific, 
pragmatic, societal and pedagogical aspects of the scientific discipline. Neglecting the practical in engineering education would turn out, not engineering experts, but bachelors and masters in the fields of mathematics, physics or chemistry; while neglecting the theoretical would turn out mere users of existing engineering machinery. Objectives such as the search for general theories, integrity, publicity and open criticism may be issues for academic education and research but the practical, societal and, especially, educational context (Heikkinen and Jaako 2010) usually defines fieldspecific criteria for the organisation of education. The educational criteria in the practical branches of science, e.g. engineering, are often based on justifications such as functionality and applicability instead of mere objectiveness or truthfulness that are emphasized in the more theoretically oriented disciplines of science (mathematics, chemistry, physics). (Heikkinen et al. 2010, Leinhardt et al. 1995)

The use of practical justifications in practical and applied disciplines is understandable and is not to be condemned out of hand. However, it is not acceptable to simultaneously apply the methodology of a certain field of science and be unaware of the restrictions of this approach. To avoid this mismatch, one should always be familiar with the characteristics of one's own discipline as well as the connections between the theoretical and the practical aspects (Heikkinen et al. 2010).

Analyses of concepts are obviously made when planning new curricula (Hiltunen et al. 2011). However, these analyses do not necessarily take both theory (i.e. principles on which a particular subject is based) and practice (i.e. action rather than ideas) into account; they are quite often very science and theory-oriented even in engineering education (so-called excessive scientification; see e.g. Beder 1999, Cañavate Avila and Lis Arias 2007, Jakobsen and Bucciarelli 2007) and only rarely the 
connections between theory and practice are explicitly described, although they may be implicitly included in the curricula.

Education in which the theoretical and practical aspects are not explicitly connected can fail to fulfil educational goals. Learning outcomes might end up being either too theoretical with no practical relevance or just a collection of heuristics without any deeper understanding of the subject. Theoretical and practical knowledge should be integrated to produce true expertise (e.g. Collin and Tynjälä 2003, Jakobsen and Bucciarelli 2007, Katajavuori et al. 2006, Leinhardt et al. 1995, Slotte and Tynjälä 2003, Tynjälä et al. 1997, Tynjälä et al. 2003, Tynjälä et al. 2005). One may even claim that the excessive scientification that has plagued engineering education since the last century (e.g. Beder 1999, Cañavate Avila and Lis Arias 2007, Jakobsen and Bucciarelli 2007) has its roots in a mismatch between the theoretical and practical sides of engineering and engineering education.

The purpose of this study is to search answers to the following questions:

- Since expertise may be defined in various ways, how should it be defined in the context of engineering education?

- If expertise is defined as integration of knowledge and skills, then which areas of engineering, particularly process engineering, can be used as integrative parts in university education?

- What are the pedagogical and curricular consequences of this integrative approach on the concept of process engineering?

On the practical level the answers to these questions mean the development of process engineering education in a way that has its foundation on the analysis of the concept of process engineering and in which the different aspects, theoretical or 
scientific, practical or professional and educational or pedagogical, of the discipline and their connections are explicitly analysed and defined in a way that enables a holistic planning of curricula. This requires a thorough consideration on the concept of process engineering and process engineering expertise in order to make the implicit connections explicit.

\section{Essential concepts}

To answer our research questions, it is necessary to define how educational and curricular concepts relevant to these questions as well as concepts of process and chemical engineering are understood. It is also noteworthy that these concepts may be considered from various perspectives and the definitions presented in this paper are not the only ones.

\subsection{Expertise}

Since the purpose of the engineering education is to produce professionals who possess, in addition to scientific expertise on a general level, expertise in a certain field of engineering, it is essential to consider what is understood by expertise and professionalism. There are several possibilities to classify the different areas of expertise (Dreyfus and Dreyfus 1986, MacLeod 1992); one example being given in Table 1.

[Table 1 near here]

In addition to the aspects presented in Table 1, there are a few general features of expertise that should be mentioned. First of all, expertise should always be considered as something more than mere knowledge, since true expertise is always a combination of various kinds of knowledge and skills (theoretical as well as practical), in which different things are truly understood, not only remembered (Buch 2007, Collin 
and Tynjälä 2003, Jakobsen and Bucciarelli 2007, Katajavuori et al. 2006). More precisely, expertise can be considered to consist of:

- theoretical, explicit, factual and conceptual knowledge (Buch 2007, Christiansen and Rump 2007, Collin and Tynjälä 2003, Katajavuori et al. 2006, Leinhardt et al. 1995, Ryle 1949, Tynjälä et al. 1997, Tynjälä et al. 2003),

- practical and procedural knowledge and skills (Collin and Tynjälä 2003, Katajavuori et al. 2006, Leinhardt et al. 1995, Ryle 1949, Tynjälä et al. 1997, Tynjälä et al. 2003),

- situational experience-based knowledge and skills (Buch 2007, Collin and Tynjälä 2003, Katajavuori et al. 2006, Tynjälä et al. 1997),

- intuitional, implicit and tacit knowledge (Balzhiser et al. 1972, Buch 2007, Collin and Tynjälä 2003, Tynjälä et al. 1997),

- reflective and metacognitive knowledge (Collin and Tynjälä 2003, Katajavuori et al. 2006, Tynjälä et al. 1997, Tynjälä et al. 2003)

- as well as knowledge that is bound to socio-cultural traditions and manners (Buch 2007, Doridot and Buch 2007, Katajavuori et al. 2006, Tynjälä et al. 2003).

Alternative ways to categorize different areas of expertise are the division to cognis (ability to describe actions), technis (ability to do/conduct describable actions) and intuis (ability to do/conduct non-describable actions) as proposed by MacLeod (1992) or cognitive (knowledge), affective (attitudes) and psychomotor (skills) areas of understanding in the taxonomy of educational objectives by Bloom (1956).

Secondly, expertise should be considered as a changing and evolving rather than static state of skills and knowledge (Katajavuori et al. 2006, Slotte and Tynjälä 2003). According to Dreyfus \& Dreyfus (1986) (see also Bereiter and Scardamalia 1993), 
when becoming an expert, a person progresses from the stage of 'novice' (a person in possession of minimal, or textbook knowledge without connecting it to practice) through stages of 'advanced beginner', 'competent' and 'proficient' to an 'expert', who is a person in possession of authoritative knowledge of discipline and deep tacit understanding across area of practice. The progress from 'novice' to 'expert' usually takes at least ten years and of course there are professionals who never reach the stage of the 'expert'. So the best we can do in university education is to turn out 'advanced beginners' or 'competent' graduates.

Thirdly, there should be a distinction between routine experts and adaptive experts, who are always trying to exceed the limits of their knowledge and skills while solving problems, whereas routine experts try to solve problems with the expertise already possessed. Because of this, it is characteristic of adaptive expertise that reforming the problem is an essential part of the problem-solving process and therefore problems are only rarely solved the way they were originally planned to be solved. (Christiansen and Rump 2007, Slotte and Tynjälä 2003) Additionally, expertise has been mentioned to include also tacit knowledge (Buch 2007, Collin and Tynjälä 2003, Mutanen 2007, Ryle 1949), social and collective knowledge (Buch 2007, Doridot and Buch 2007, Katajavuori et al. 2006, Slotte and Tynjälä 2003, Tynjälä et al. 2003) and skills to combine different areas of knowledge (Jakobsen and Bucciarelli 2007). In engineering expertise in particular, skills and knowledge are connected with discipline specific artefacts and their design (Ravesteijn et al. 2006, Tynjälä et al. 2003).

Regardless of the criteria according to which the expertise is divided into different areas, it is essential for true expertise to include different areas as an integrated entity; and if expertise is considered to be a goal in academic engineering education, it is vital to take this aim into account already during the planning of the education and 
curriculum. (e.g. Collin and Tynjälä 2003, Jakobsen and Bucciarelli 2007, Katajavuori et al. 2006, Leinhardt et al. 1995, Slotte and Tynjälä 2003, Tynjälä et al. 1997, Tynjälä et al. 2003, Tynjälä et al. 2005) True expertise is not achieved in traditional academic education which is plagued by excessive scientification as mentioned earlier. It is not merely enough to create lists of intended learning outcomes (such as the one presented in Table 1), but one should also consider how to create explicit connections between theoretical and practical aspects while planning a curriculum for the engineering Master programmes (Jakobsen and Bucciarelli 2007, Tynjälä et al. 1997). Therefore the concept of integration should also be considered.

\subsection{Integration in planning of curricula}

Integration in planning of curricula is understood as an organisation of courses and/or programmes into larger entities where aspects from various disciplines are brought together in order to create multidisciplinary approaches. From the students' perspective, it means that the connections of theory and practice are made explicit in a way that enables students to improve their expertise. (Abbas and Romagnoli 2007, Katajavuori et al. 2006) Although the benefits of the integrated education can be justified from various perspectives (e.g. engineering expertise, pedagogics and extents of curricula) (e.g. Abbas and Romagnoli 2007, Beder 1999, Christensen et al. 2007, Christiansen and Rump 2008, Collin and Tynjälä 2003, Giralt et al. 1994, Griffiths and Guile 2003, Guile and Griffiths 2001, Jakobsen and Bucciarelli 2007, Jiles et al. 2002, Katajavuori et al. 2006, Leinhardt et al. 1995, MacLeod 1992, Paladini 2004, Prausnitz 1998, Rugarcia et al. 2000, Slotte and Tynjälä 2003, Turek and Miština 2007, Tynjälä et al. 2003, Woods and Sawchuk 1993), only one benefit is emphasized here: integrated education creates explicit connections between theory and practice and therefore enhances students' motivation towards their studies and enables the development of holistic expertise that 
is essential in engineering expertise (Collin and Tynjälä 2003, Giralt et al. 1994, Griffiths and Guile 2003, Guile and Griffiths 2001, Leinhardt et al. 1995, Prausnitz 1998, Rugarcia et al. 2000, Slotte and Tynjälä 2003, Tynjälä et al. 2003). Integrative pedagogics and connective model (Collin and Tynjälä 2003, Griffiths and Guile 2003, Guile and Griffiths 2001, Leinhardt et al. 1995, Rugarcia et al. 2000, Slotte and Tynjälä 2003, Tynjälä et al. 2003) as well as transfer of knowledge (Christiansen and Rump 2008, Jakobsen and Bucciarelli 2007) have been used to describe and explain this phenomenon.

The integration can be implemented in different ways and it is not possible to point out a single "correct method" for integration (Abbas and Romagnoli 2007, Katajavuori et al. 2006). Concepts of horizontal and vertical integration are often used to describe curricular integration which creates connections either between courses with different goals and contents that are taught at the same time (horizontal integration) or between courses with similar content and different time (vertical integration) (Abbas and Romagnoli 2007, Guile and Griffiths 2001, Paladini 2004, Prausnitz 1998).

Tools and methods for horizontal integration are usually based on using purposeful teaching methods whereas vertical integration often requires educational development on the curricular level in addition to the purposeful teaching methods. Educational tools that have been used to improve (mainly horizontal but also vertical) integration are e.g.:

- application of theories and revision of theoretical topics in new practical applications (Tynjälä et al. 2003),

- learning by doing (simulations, laboratory exercises, etc.) (Giralt et al. 1994, Tynjälä et al. 2003), 
- reflective learning (e.g. portfolios and guided practical training) (Giralt et al. 1994, Leinhardt et al. 1995, Tynjälä et al. 2003),

- use of kernel concepts (Griffiths and Guile 2003),

- tutoring, mentoring and social learning (Leinhardt et al. 1995, Tynjälä et al. 2003)

- as well as project-, problem- or work-based learning using authentic examples, methods and problems (Abbas and Romagnoli 2007, Christiansen and Rump 2008, Collin and Tynjälä 2003, Jakobsen and Bucciarelli 2007, Leinhardt et al. 1995, Slotte and Tynjälä 2003, Tynjälä et al. 2003).

At the curricular level, the most effective tools for vertical integration are basic courses of engineering (not in mathematics or natural sciences!) at the very beginning of studies (Blicblau and Bitterfeld 1994, Hiltunen et al. 2011, Jiles et al. 2002, Livshits and Sandler 1998, Woods and Sawchuk 1993) as well as explicit streams or themes that continue through the studies and that will lead to certain learning outcomes relevant for a professional engineer (e.g. design skills and problem-solving skills) (Abbas and Romagnoli 2007, Blicblau and Bitterfeld 1994, Hiltunen et al. 2011, Jakobsen and Bucciarelli 2007, Jiles et al. 2002, Livshits and Sandler 1998, Woods and Sawchuk 1993). Use of basic courses and streams can also be justified based on Bloom's taxonomy of educational objectives (Bloom 1956, Krathwohl et al. 1964) and Ausubel's advance organizers (Ausubel 1960, Ausubel et al. 1978). The challenges that are encountered with the basic engineering courses (as well as with the use of advance organizers in general (Ausubel 1960, Ausubel et al. 1978)) are related to outlooks according to which applications can be learned only after a period of formal learning has taken place. These views have their roots in the excessive scientification of the engineering curricula and they lose their justifications when one accepts that the 
fundamentals of engineering can be taught and learned also on a descriptive/qualitative level without the need for mathematics. Obviously mathematics and its applications must be included in engineering curricula at some point but there is no particular need to begin engineering curricula with anything but engineering itself. (Blicblau and Bitterfeld 1994, Hiltunen et al. 2011, Jiles et al. 2002, Livshits and Sandler 1998, Woods and Sawchuk 1993)

Whereas both horizontal and vertical integration are commonly used to integrate different areas of education within a curriculum, it is also possible - and in practical disciplines such as engineering also necessary - to consider the connections between academic and professional activities. These considerations are necessary if higher engineering education wishes to be both academically credible and societally useful. (Gobin 1987, Teichler and Kehm 1995) The key issue in these considerations is the definition of universities' tasks: research (i.e. gaining expertise on a certain discipline), education (i.e. spreading expertise to the future generations) and societal impact (i.e. use of this expertise in the society). From the education's perspective, it is also essential to consider how the expertise is assumed to be created and improved. (Tynjälä et al. 2003) A pragmatic way of thinking, as well as situational and sociocultural learning support close interaction between universities and society, industry and commerce (Katajavuori et al. 2006, Tynjälä et al. 2003). However, interaction between universities and industry has also its challenges. Even if unwillingness that might become a major obstacle on either side (Griskey 1991) is avoided, there is always a challenge to adjust educational, research and practical objectives with each other (Livshits and Sandler 1998). Possible methods for co-operation between universities and industry are e.g. industrial visits and excursions (Gobin 1987), common projects (Gobin 1987), theses (Gobin 1987), work- 
based learning (Tynjälä et al. 2003), practical training (Guile and Griffiths 2001, Katajavuori et al. 2006) and lecturers from the industry (Felder 1987).

To sum up, one can conclude that planning of curricula in higher engineering education requires both horizontal and vertical integration as well as explicit connections between education and research and co-operation with society and industry (Guile and Griffiths 2001). To achieve this, it is necessary to know the links between education, research and practice. To find these links in the process engineering, the concepts of process and chemical engineering are considered.

\subsection{Concepts of process and chemical engineering}

The concepts of chemical engineering and process engineering are linked with each other, but their relation is not unambiguous. Sometimes these two concepts are considered as synonyms and sometimes one is considered to be a sub-category of the other. If chemical engineering is considered as a larger concept that includes various industrial procedures (that include chemical reactions at one point or another) as well as design, operation, control, theories, models and generalisations about these procedures, then process engineering is usually understood as a subcategory that is associated with the practical aspects of these industrial processes (Abbas and Romagnoli 2007). However, it is also possible to consider process engineering as a larger concept that covers all the practical and theoretical aspects of the engineering discipline associated with different kind of industrial processes (whether they include chemical reactions or not), in which case chemical engineering is perceived as a sub-category comparable to e.g. mechanical process engineering (Hiltunen et al. 2011). In our paper's context (Department of Process and Environmental Engineering at the University of Oulu, Finland) process engineering is considered to include not only chemical and mechanical process engineering, but also automation and environmental engineering. Therefore, it 
is more meaningful to use the latter perspective, although it is acknowledged that the other approach is also widely used. Due to the closeness of these two concepts, characteristic features of both process and chemical engineering are presented. Additionally, some aspects that are usually connected with the concept of chemical engineering are here considered to be characteristic to process engineering, too.

In chemical engineering, the importance of being familiar with the characteristic features of one's own discipline was emphasized as early as the 1920s by Warren K. Lewis and team in "The Principles of Chemical Engineering", in which they presented the concept of unit operations. In the following decades the idea of unit operations, together with general phenomenon-based approach, became a feature that still defines the concept of chemical engineering. (Griskey 1991, Prausnitz 1998) Chemical engineering expertise has traditionally been considered to consist of certain scientific and engineering fundamentals such as mass and energy balances, thermodynamics, phase equilibria, transport phenomena, separation processes, reactor design, experimental design, measurements, analyses and data processing, which have formed a foundation for the chemical engineering curricula (Felder 1987). There have also been claims that the duties of a chemical engineer are nowadays so fragmented that it is quite possible that some chemical engineers will never need these fundamentals (Chipman 1949, Coyle et al. 2007, Rugarcia et al. 2000) and therefore in education one should concentrate more on economic, administrative and societal aspects of the engineer's work (Becker 2006, Paladini 2004, Prausnitz 1998, Ravesteijn et al. 2006) as well as on automation, environmental aspects and safety issues (Delahousse 2007b, Prausnitz 1998, Rugarcia et al. 2000) that are all currently neglected due to the large role of natural sciences and technical details in engineering curricula (Becker 2006, Jiles et al. 2002, Paladini 2004, Ravesteijn et al. 2006, Rugarcia et al. 2000). 
Process engineering can be considered to be more or less synonymous with chemical engineering. Key elements in the process engineering are unit operations, phenomenon-based approaches, big role of research and design methods (e.g. simulation and modelling) as well as a growing need for holistic approaches in which the industrial processes and their products (artefacts) are considered as an entity that has connections with the surrounding society. These connections must be understood in order to justify the existence of process (or chemical) engineering, since its value is only related to the value it gives to society (Prausnitz 1998).

Concerning the areas of expertise within process engineering (i.e. the focus of this study), surveys made by TEK (Tekniikan Akateemiset - Academic Engineers and Architects in Finland) have shown, that the skills required from the process engineers graduating from Finnish universities are very similar to the ones presented in Table 1 (Harmaala 2012).

\section{Triangular approach to the connections within the concept of process engineering}

Based on the previous chapters, one may conclude that engineering expertise is a complex subject that contains knowledge, skills and attitudes some of which are general and some specific to the discipline. Furthermore, the education of engineers requires a curriculum that integrates various aspects of this expertise into a meaningful entity with explicit connections between the different areas of engineering. To achieve a thorough understanding of the connections within a concept of process engineering, its status should be considered from all the relevant perspectives. As an engineering discipline, there is a practical aspect in process engineering that should be covered in addition to the theoretical one. Furthermore, if the theoretical perspective is regarded as an academic activity, it should cover both research and education that are traditionally the 
tasks of universities. The concept of process engineering should thus cover its meaning as a practical (i.e. industrial) activity as well as a theoretical (i.e. academic or scientific) activity in both research and education.

The concept of process engineering, as illustrated as a triangle with its three aspects (research, education and practice) located in the corners, is presented in Figure 1. This kind of triangular approach has already been used to evaluate one area of process engineering (i.e. process metallurgy) (Heikkinen et al. 2010), and this chapter presents an extension to this analysis. Whereas the previous study was focused only on the concept of process metallurgy and evaluated the consequences of the approach into metallurgical research (Heikkinen et al. 2010), the purpose of this study is to apply the same approach to the concept of process engineering in general and to consider the curricular and pedagogical consequences of this approach.

[Figure 1 near here]

Figure 1, in which the different aspects of process engineering are presented, also presents the features that are characteristic for different perspectives. In this analysis, research is considered to be connected with different scientific methodologies, whereas the education is related to the curricula. For its part, practice is strongly linked with different kinds of industrial applications (e.g. unit operations mentioned in chapter 2.2). The phenomena that are researched as well as taught and studied in order to understand and control the industrial processes (e.g. chemical reactions, transport phenomena) are common to both education and research and therefore create a link between the two. A link between research and practice is formed by individual cases (e.g. R\&D projects), whereas educational methods in which actual problems and cases are integrated with pedagogical aspects (e.g. by using problem-based learning; PBL) create the link between education and practice. In this triangular approach, the research 
corner represents the general academic expertise and practical corner represents the general professional as well as specific engineering expertise presented in Table 1. The educational corner represents those areas that a teacher must master in order to plan and implement meaningful educational entities.

Two things that are common to research, education and practice (and could therefore be chosen as links between all three corners in Figure 1) are the goals towards which the activities are directed and tools/methods that are used to achieve these goals (e.g. simulation and modelling as well as experimental research). In this paper, the purpose is to evaluate the consequences of this approach to educational activities and therefore tools were chosen to be included in Figure 1 instead of goals. In a more vision-orientated study one could consider goals (as well as values behind the goals) instead or in addition to tools (cf. Figure 2).

[Figure 2 near here]

Figure 1 offers several possibilities to investigate different aspects of process engineering. One could, for instance, draw projections to the triangle in order to take a closer look on the connections between practice, education and research. While drawing these projections one should keep in mind that the applied nature of the engineering sciences is lost unless the practice corner is taken into account. Therefore all the projections within this study were drawn from the practice corner in which the industrial applications are located.

The first projection (presented in Figure 3) represents a research-relevant approach, in which a connection between practical applications and theoretical research is presented through those cases in which the practical relevance and profitability must be considered together with actual case-related problem solving. The cases are connected with applications that could be related to either processes (i.e. process 
development), environment (i.e. environmental and sustainability investigations) or materials (i.e. products, raw materials, waste, refractory materials etc.) as well as research methodologies that are dependent upon the field of science (and its paradigms) as well as ontological and epistemological bases of the research (i.e. philosophical considerations concerning the nature of knowledge and research subject).

[Figure 3 near here]

Figure 4 illustrates an educationally relevant projection in which the connection between education (curriculum) and practice (applications) is illustrated via practiceorientated teaching methods such as problem-based learning. Since research and study are both activities that aim for new and improved knowledge, it is advisable to have many similarities between Figures 3 and 4. In addition to identical top level applications there are similarities in other levels, too. Practical relevance and problem solving are relevant in both engineering research cases and problem-based learning. However, considerations concerning profitability that play a major role in research and development cases are not as relevant in education. Therefore, these considerations are replaced by pedagogical ones in problem-based learning and other practically oriented teaching methods which create a link between practical and theoretical levels in Figure 2, much as the R\&D-cases do in the research-based projection presented in Figure 3. The bottom level of Figure 4 (curricula) is considered to consist of goals (learning outcomes), subjects (the substance) and obviously the students at whom the education is aimed.

[Figure 4 near here]

The problem with the projections presented in Figures 3 and 4 is the separation of education and research as two separate areas of academic activities. To maintain the connection (i.e. to ensure the research-based education and to educate qualified 
researchers for the future), it is more reasonable to create a projection from the practical corner to the side between research and education. This projection is presented in Figure 5 and it represents an academically relevant approach to the concept of process engineering.

[Figure 5 near here]

The top level in Figure 5 representing the applications (i.e. processes, environment and materials) is similar to ones presented in Figures 3 and 4 . The bottom level illustrates the phenomena that are common in research and education. In this analysis the phenomena were divided into three categories: chemical phenomena (basically chemical reactions as well as thermodynamic and kinetic considerations of these reactions), physical phenomena (including e.g. mechanical and transport phenomena as well as structural changes such as phase transformations and transitions) and mathematical-logical phenomena (that are considered to cover all abstract and nonnatural phenomena involved in process engineering). These phenomena are investigated and explained by experimental, analytical and modelling tools (both static and dynamic) that are used to apply the phenomenon-based considerations into practical applications. Figure 5 can be seen to include the features that traditionally are considered to be characteristic to process (or chemical) engineering (cf. chapter 2.2). Additionally, it gives a possibility to explicitly present the connections between process engineering and its neighbouring disciplines, such as environmental engineering, automation and control engineering and materials science. More importantly, it clarifies the roles of mathematics, physics and chemistry in engineering, which are too often left too implicit for students to comprehend and use. Design, which is a key issue in all the engineering disciplines, is not explicitly presented in Figures 1 to 5, although it is possible to define 
the expertise in engineering design as an ability to master the things as well as connections presented in Figures 1 to 5.

This analysis on the concept of process engineering is broadened from the previous analysis on the concept of process metallurgy (Heikkinen et al. 2010) and it seems that this generalization is possible without any larger modifications of the actual analysis. This gives a reason to believe, that the analysis presented in Figures 1 to 5 may also be applied to other disciplines with practical relevance (e.g. medicine or education). Obviously the phenomena, the tools and the applications of, for instance, educational psychology or dentistry differ drastically from the ones of process engineering, but it does not change the fact that the nature of all these disciplines could be considered by analysing the phenomena that are studied, the tools that are used and the applications that are researched.

\section{Results and discussion}

Since integrated education is necessary for integrated expertise, the most important advantage of the triangular approach is that it enables the integration by creating visible links between the different areas of process engineering. The most obvious consequence of the triangular approach is the emphasis of methodological expertise. The choice of methods and methodological expertise as a core content of process engineering education is justified not only by their role in creating links between theoretical and practical aspects of the discipline, but also because the different methods of research and development (such as modelling, simulation, experiments and analyses) always have an essential role in process engineering. Additionally, connection of theory and practice using methodological exercises is important in engineering education, because the context in which the theory is connected to technological applications (i.e. artefacts) is a key element that differentiates engineering from other sciences. It is more 
motivating for the engineering students to have courses in which theory is not separated from the applications.

The integration does not have to be more complicated than telling students about the connections presented in the previous chapter, although it is possible - and more efficient - to implement larger pedagogical developments in teaching and assessment based on the triangular approach. The emphasis on the methodological expertise may have its influence on the learning outcomes of the whole programme and on the goals, contents and educational methods of individual courses as well. In other words, the consequences of the triangular approach may be either pedagogical (horizontal integration) or curricular (vertical integration).

\subsection{Pedagogical consequences of the analysis}

Two examples of horizontal integration that have been executed in the programmes of process and environmental engineering at the University of Oulu are as follows:

- Changes in teaching and assessment methods used in the course of 'Introduction to process engineering' (5 ECTS) directed to the first year students of process engineering have been made. The old methods were based on lectures and terminal written exams and they were replaced by a continuous assessment in which a small groups of students ( 2 to 4 students in each group) are required to examine a certain process (e.g. production of stainless steel, chemical pulp, champagne or sulphuric acid) from different perspectives by using the methods of process engineering (i.e. creating mass and energy balances, considering the unit operations of the process chain as well as identifying chemical, mechanical and transport the phenomena involved in these operations, evaluating the possibilities for automation and so on). These changes have made it possible to 
better align teaching and assessment methods with the contents and learning outcomes of the course. It is now possible for the students to use the methodology of process engineering from the very beginning of their studies and therefore to see the connections between the theories and practices of process engineering.

- Two courses of physical chemistry organized by the faculty of science were replaced with engineering oriented courses of 'Material and energy balances' ( 5 ECTS) and 'Thermodynamic equilibria' (5 ECTS), in which the contents were very similar to the old courses, but in which thermodynamics was not considered as a pure science, but as a tool for process design. The connection between the theories of physical chemistry and process development was obtained by choosing such teaching and assessment methods that have relevance in actual engineering work. In other words, the goals of the new courses were not only to learn the fundamentals of physical chemistry, but to define chemical equilibria of the systems relevant to industrial processes and also to understand the relevance of equilibria (and their computational determination) as a part of process analysis, planning and control. So instead of lectures and terminal written exams, the new courses consist mainly of exercises and simulations that are based on authentic engineering problems. Two important features in these exercises are that:

- $\quad$ the students are allowed to use the very same methods and tools that are used in real research and development (e.g. computational thermodynamics, CTD, software) and the problem solving is not limited to mere calculation (i.e. application of mathematics and chemistry), but it also contains elements in which 
computationally solvable problems are created based on verbal real-life problems that in themselves are not solvable computationally.

The results of these changes have been convincing. All the courses in which the contents as well as teaching and assessment methods have been re-considered based on the triangular approach have had pass rates of between 92 and $97 \%$ every year. As a comparison, in 2005, the last year when the old courses of physical chemistry (cf. above) were included in the curriculum, only $14.4 \%$ of the students of process engineering managed to pass both of the physical chemistry courses within one year of the first possibility to do so. It is likely that the improvements in the pass rates are due to many changes in areas such as teaching and evaluation methods in addition to the integration of theory and practice and taking the engineering context into account. The student feedback concerning the changes, which has been very positive, indicates that the integration of theory into the engineering context as well as the emphasis on methods has a major role in students' motivation (the following comments are from the second year students of process engineering; translated from Finnish):

Concerning the integration of theory into engineering practice: “As a learner I prefer courses like this. It feels like I'm building a foundation of knowledge and expertise for future studies and work"

Concerning the emphasis on methods: "Real-life problems forced to think the answers properly. That is more educational and also more challenging."

The same indication is also seen in the answers of the first year students who participated on a course of "Introduction to process engineering"; when asked how well the course gave them a holistic view on the process engineering, $75-82 \%$ of the students (depending on the year) answered that the integration of different areas worked well and made learning easier. The role of engineering context in the education of mathematics 
and thermodynamics has been considered in more detail in our previous study (Heikkinen and Jaako 2010).

Corresponding changes in teaching and evaluation methods have also been made in other courses of the process and environmental engineering programmes at the University of Oulu. One example concerning the change towards continuous assessment in one of the courses of these programmes is presented in more detail by Jaako (2014).

It should also be noted that the role of simulation and other methodological exercises is different in different stages of curriculum. In the beginning, they can be used to illustrate different processes and phenomena in a descriptive way. One could, for example, use CTD and its results to examine the effects of temperature and pressure on a certain chemical reaction. Later on, these kinds of exercises can be deepened by giving more emphasis on the actual analytical methods that are used in process engineering: one could, for example, pay more attention to the rules of physical chemistry that are used in CTD and hence clarify the possibilities as well as restrictions and boundaries of the used methods. Further on, it is possible to use larger exercises of process design in which e.g. CTD is one tool among the others and which aim to give students more holistic view on the discipline. Finally, students should be allowed to use their skills and knowledge on the actual engineering problems in different areas of process engineering. Obviously it is possible to use analogous approach for other methods of process engineering (such as computational fluid dynamics, CFD) as well.

In addition to simulation, laboratory exercises offer a great way to integrate theory and practice via learning of methods. In the context of process and environmental engineering programmes at the University of Oulu, laboratory 
exercises are mostly incorporated within courses rather than being separate courses of their own.

\subsection{Curricular consequences of the analysis}

Although it is possible - and beneficial - to develop engineering education using horizontal integration on the course-level alone (as shown in previous chapter), it is much more efficient to aim for true integration by building the curricular structure as well as individual courses based on links between the different areas of the discipline. According to the analysis presented in chapter 3, the connecting links in the process engineering are the tools and the methods which, on the one hand, are used to understand and control the industrial applications, but which on the other hand are tools to create and validate theories. Without knowledge about these links, it is not possible to create meaningful integration. The significant role of tools and methods in process engineering is not very surprising, since some sorts of methods are always needed in order to control any kind of process.

In addition to curricular integrity that can be achieved by knowing the connecting links of one's own discipline, it is possible to use the triangular approach to create connections between education, research and industrial practices, since the methods of process engineering (that act as links) are not limited to education or academic activities.

At the University of Oulu, the triangular approach was used while creating a curricular structure for Bachelor and Master programmes of process and environmental engineering. The most noticeable consequences are the streams that connect studies from different stages of the curriculum and lead to learning outcomes that are relevant for a process engineer (cf. Table 1) as well as fundamental courses that begin these streams (Hiltunen et al. 2011). Other implications worth mentioning are the increased 
role of experimental and simulation tools and methods on various courses with an aim to bring education and research closer to one another.

The learning outcomes, towards which the streams are aimed at, are chosen to correspond to methodological expertise relevant to process engineers. These learning outcomes are:

- Ability for phenomena-based modelling and design (both static and dynamic simulation) in the context of process and environmental engineering (including the ability to investigate physical, chemical, biological and geoscientific phenomena).

- Ability to control industrial processes and take their technical, economic, legal and safety issues into account.

- Ability to estimate and control the environmental impacts of industrial and community processes.

- Ability to use automation and control engineering in the context of process and environmental engineering.

- Non-technical skills required in engineering design, research, development and education (including e.g. social and multicultural skills).

Integrated expertise in these fields requires connections between theory and practice - or knowledge and skills - which, in the programmes considered in this paper, are learned via integrative teaching methods such as laboratory and simulation exercises, seminars and theses as well as during practical training.

\section{Conclusions}

A triangular approach to analyze the different aspects of process engineering is proposed as a method to integrate engineering education and to obtain integrated 
expertise for engineering students. Based on this analysis, methodological skills as well as integration of theory into the engineering context are emphasized. The usefulness of this approach is considered by applying the results of the approach on the pedagogical and curricular development implemented in the bachelor and master programmes of process engineering at the University of Oulu in Finland. The results from this development work indicate that the approach is suitable for engineering education development: the passing percentages have improved considerably and the student feedback indicates that the emphasis on methods and integration of theory into engineering context has a major role in students' motivation. The proportions of students passing the courses have been high and the student feedback concerning the new approach has been positive. Although the evidence on the effects on the curricular level are much more difficult to define, the authors feel that the results are best in situations in which the approach is applied on a larger scale rather than individual courses. This opinion can be justified because the main purpose of the triangular approach was to clarify the connections between the different areas of a discipline and hence enhance the integration in education.

One should also note that the aim of this paper was not to create a flawless or exclusive definition for the concept of process engineering but to give an example how the connections between the different aspects of a certain discipline can be presented explicitly and how this approach may be used in educational development.

In addition to the application of the triangular approach towards the process engineering on the pedagogical and curricular development presented in this article, the analysis may as well be used when evaluating and developing the research practices of the discipline. This has already been done in the narrower field of process metallurgy. 


\section{Acknowledgements}

The authors wish to thank Dr. Juha Ahola, Prof. Timo Fabritius and Mr. Esko Juuso for their contribution in the planning and implementation of the educational and curricular issues presented in this paper.

\section{References}

Abbas, A. and Romagnoli, J.A., 2007. Curriculum intensification through integration of units of study in the chemical engineering degree programme. Transactions of IChemE. Part D. Education for chemical engineers. 2 (1), 46-55.

Ausubel, D., 1960. The use of advance organizers in the learning and retention of meaningful verbal material. Journal of educational psychology. 51 (5), 267-272.

Ausubel, D., Novak, J. and Hanesian, H., 1978. Educational psychology: A cognitive view. New York: Holt, Rinehart and Winston.

Balzhiser, R., Samuels, M. and Eliassen, J., 1972. Chemical engineering thermodynamics. The study of energy, entropy and equilibrium. Englewood Cliffs, New Jersey: Prentice-Hall Inc.

Becker, F.S., 2006. Globalization, curricula reform and the consequences for engineers working in an international company. European journal of engineering education. 31 (3), 261-272.

Beder, S., 1999. Beyond technicalities: expanding engineering thinking. Journal of professional issues in engineering education and practice. 125 (1), 12-18.

Bereiter, C. and Scardamalia, M., 1993, Surpassing Ourselves: An Inquiry into the Nature and Implications of Expertise. Chicago, IL: Open Court.

Biggs, J. and Tang, C., 2007. Teaching for Quality Learning at University. Maidenhead, UK: Open University Press/Mc Graw-Hill Education.

Blicblau, A. and Bitterfeld, G., 1994. Relating science to engineering: employing a materials approach. European journal of engineering education. 19 (2), 191196.

Bloom, B. ed., 1956. Taxonomy of educational objectives. The classification of educational goals. Handbook 1: Cognitive domain. New York: David McKay Company, Inc. 
Bomke, W., 2007. Engineers of the Renaissance and the concept of "the New Renaissance Engineer”. In: S.H. Christensen, M. Meganck and B. Delahousee, eds. Philosophy in Engineering. Århus: Academica, 29-40.

Buch, A., 2007. Knowledge and learning in engineering practice. In: S.H. Christensen, M. Meganck and B. Delahousee, eds. Philosophy in Engineering. Århus: Academica, 161-177.

Cañavate Avila, J. and Lis Arias, M., 2007. Current problems in engineering historically rooted in the search for status as a profession. In: S.H. Christensen, M. Meganck and B. Delahousee, eds. Philosophy in Engineering. Århus: Academica, 369390.

Chipman, J., 1949. What is metallurgy? Metals transactions. 185, 349-354.

Christensen, S.H., Meganck, M. \& Delahousse, B., 2007. Occupational Bildung in Engineering Education. In: S.H. Christensen, M. Meganck and B. Delahousee, eds. Philosophy in Engineering. Århus: Academica, 13-22.

Christiansen, F.V. and Rump, C., 2007. Getting it right: conceptual development from student to experienced engineer. European journal of engineering education. 32 (4), 467-479.

Christiansen, F.V. and Rump, C., 2008. Three conceptions of thermodynamics: technical matrices in science and engineering. Research in science education. 38 (5), 545-564.

Collin, K. and Tynjälä, P., 2003. Integrating theory and practice? Employees' and students' experiences of learning at work. Journal of workplace learning. 15 (7), 338-344.

Coyle, E., Murphy, M. and Grimson, W., 2007. Engineering science as opposed to natural science and applied science. In: S.H. Christensen, M. Meganck and B. Delahousee, eds. Philosophy in Engineering. Århus: Academica, 139-160.

Delahousse, B., 2007a. The roles and status of the new engineer in a global knowledge society. In: S.H. Christensen, M. Meganck and B. Delahousee, eds. Philosophy in Engineering. Århus: Academica, 311-313.

Delahousse, B., 2007b. Industry requirements for the new engineer. In: S.H. Christensen, M. Meganck and B. Delahousee, eds. Philosophy in Engineering. Århus: Academica, 315-337. 
Doridot, F. and Buch, A., 2007. The philosophy and epistemology of engineering practice and engineering science. In: S.H. Christensen, M. Meganck and B. Delahousee, eds. Philosophy in Engineering. Århus: Academica, 85-88.

Dreyfus, H. and Dreyfus, S., 1986. Mind Over Machine: The Power of Human Intuition and Expertise in the Era of the Computer. New York: The Free Press, 50.

Felder, R., 1987. The future ChE curriculum. Must one size fit all? Chemical engineering education. 21 (2), 74-77.

Felder, R., Woods, D., Stice, J. and Rugarcia, A., 2000. The future of engineering education. Part 2. Teaching methods that work. Chemical engineering education. 34 (1), 26-39.

Giralt, F., Medir, M., Thier, T. and Grau, F., 1994. A holistic approach to ChE education. Part 1. Professional and issue-oriented approach. Chemical engineering education. 28 (2), 122-127.

Gobin, R., 1987. The role of industry in the education of mechanical engineers. European journal of engineering education. 12 (3), 253-257.

Griffiths, T. and Guile, D., 2003. A connective model of learning: the implications for work process knowledge. European Educational Research Journal. 2 (1), 56-73.

Griskey, R., 1991. Undergraduate education. Where do we go from here? Chemical engineering education. 25 (2), 96-97.

Guile, D. and Griffiths, T., 2001. Learning through work experience. Journal of education and work. 14 (1), 113-131.

Harmaala, K. (ed.), 2012. Tekniikan yliopistokoulutusta kehittämässä - Raportti vastavalmistuneiden palautteesta ja työseminaarin keskustelusta. Tekniikan Akateemiset TEK. 45. [In Finnish]

Heikkinen, E.-P., Fabritius, T. and Riipi, J., 2010. Holistic analysis on the concept of process metallurgy and its application on the modelling of the AOD process. Metallurgical and materials transactions B. 41B (4), 758-766.

Heikkinen, E.-P. and Jaako, J., 2010. Context-free education - mission: impossible. In: E. Myller, ed. Reflektori 2010 - Symposium of Engineering Education, Espoo: Aalto University, Lifelong Learning Institute Dipoli, 79-88.

Hiltunen, J., Heikkinen, E.-P., Jaako, J. and Ahola, J., 2011. Pedagogical basis of DAS formalism in engineering education. European journal of engineering education. $36(1), 75-85$. 
Jaako, J. 2014. Controlling the didactic relation: a case in process engineering education. European journal of engineering education. 39 (4), 448-462.

Jakobsen, A. and Bucciarelli, L., 2007. Transdisciplinary variation in engineering curricula. Problems and means for solutions. European journal of engineering education. 32 (3), 295-301.

Jiles, D., Akinc, M., Biner, S., Constant, K., Gray, J., Huba, M., Martin, S., Schmerr, L. and Thompson, R., 2002. Vertically integrated engineering design for combined research and curriculum development in materials engineering and nondestructive evaluation. Quantitative nondestructive evaluation. 615 (1), 2035-2041.

Katajavuori, N., Lindblom-Ylänne, S. and Hirvonen, J., 2006. The significance of practical training in linking theoretical studies with practice. Higher education. $51(3), 439-464$.

Krathwohl, D., Bloom, B. and Masia, B. eds., 1964. Taxonomy of educational objectives. The classification of educational goals. Handbook 2: Affective domain. New York: David McKay Company, Inc.

Leinhardt, G., McCarthy Young, K. and Merriman, J., 1995. Integrating professional knowledge: the theory of practice and the practice of theory. Learning and instruction. 5 (4), 401-408.

Livshits, V. and Sandler, B.Z., 1998. Contradictory tendencies in engineering education. European journal of engineering education. 23 (1), 67-77.

MacLeod, I., 1992. The competence of an Ingenieur. European journal of engineering education. 17 (4), 361-369.

Martin, R., Maytham, B., Case, J. and Fraser, D., 2005. Engineering graduates' perceptions of how well they were prepared for work in industry. European journal of engineering education. 30 (2), 167-180.

Mittelstrass, J., 2006. The future of the university and the credibility of science and scholarship. Ethical perspectives: Journal of the European Ethics Network. 13 (2), 171-189.

Mutanen, A., 2007. Methodology of engineering science as a combination of epistemic, ethical and aesthetic aspects. In: S.H. Christensen, M. Meganck and B. Delahousee, eds. Philosophy in Engineering. Århus: Academica, 123-138.

Nygaard, C., Højlt, T. and Hermansen, M., 2008. Learning-based curriculum development. Higher education. 55 (1), 33-50. 
Paladini, E.P., 2004. Shaping behaviour: strategies for getting students involved in engineering programmes. European journal of engineering education. 29 (1), 125-138.

Prausnitz, J.M., 1998. Chemical engineering and the other humanities. Chemical engineering education. 32 (1), 14-19.

Ravesteijn, W., de Graaff, E. and Kroesen, O., 2006. Engineering the future: the social necessity of communicative engineers. European journal of engineering education. 31 (1), 63-71.

Rugarcia, A., Felder, R., Woods, D. and Stice, J., 2000. The future of engineering education. Part 1. A vision for a new century. Chemical engineering education. 34 (1), 16-25.

Ryle, G., 1949. The concept of mind. London: Hutchinson's University Library.

Slotte, V. and Tynjälä, P., 2003. Industry-university collaboration for continuing professional development. Journal of education and work. 16 (4), 445-464.

Teichler, U. and Kehm, B., 1995. Towards a new understanding of the relationships between higher education and employment. European journal of education. 30 (4), 115-132.

Turek, I. and Miština, J., 2007. Globalization and its impacts on engineering education. In: S.H. Christensen, M. Meganck and B. Delahousee, eds. Philosophy in Engineering. Århus: Academica, 391-408.

Tynjälä, P., Nuutinen, A., Eteläpelto, A., Kirjonen, J. and Remes, P., 1997. The acquisition of professional expertise - a challenge for educational research. Scandinavian journal of educational research. 41 (3), 475-494.

Tynjälä, P., Välimaa, J. and Sarja, A., 2003. Pedagogical perspectives on the relationship between higher education and working life. Higher education. 46 (2), 147-166.

Tynjälä, P., Salminen, R., Sutela, T., Nuutinen, A. and Pitkänen, S., 2005. Factors related to study success in engineering education. European journal of engineering education. 30 (2), 221-231.

Woods, D. and Sawchuk, R., 1993. Knowledge structure: Fundamentals of chemical engineering. Chemical engineering education. 27 (2), 80-85. 
Table 1. Different areas of expertise pursued in academic/scientific engineering education. 
Figure 1. Different aspects of process engineering and their characteristic features.

Figure 2. Different aspects of process engineering and their characteristic features as well as values and goals behind these aspects.

Figure 3. Research-relevant projection of the concept of process engineering.

Figure 4. Educationally relevant projection of the concept of process engineering.

Figure 5. Academically relevant projection of the concept of process engineering. 